\title{
A practical tip to engage the left main coronary artery in patients presenting with aortic aneurysms
}

\author{
Kudret Keskin, Serhat Sığırcı *, Süleyman Sezai Yıldız, Gökhan Çetinkal, Kadriye Kılıçkesmez \\ Şişli Hamidiye Etfal Education and Research Hospital, Department of Cardiology, Turkey
}

\section{A R T I C L E I N F O}

\section{Article history:}

Received 23 September 2017

Received in revised form 9 October 2017

Accepted 10 October 2017

Available online 16 October 2017

\section{Keywords:}

Coronary angiography

Aortic dilatation

Cardiac catheterization

\begin{abstract}
A B S T R A C T
Coronary angiography in patients presenting with ascending aortic aneurysms can be challenging since standard catheters may fail to reach the left main coronary artery. A widely accepted approach is the mother-in-child catheter technique whereby a catheter with a smaller diameter is telescoped through one with a bigger diameter, a procedure that helps to lengthen the catheter. However, this technique is associated with several disadvantages such as thrombus formation within the catheters, inadvertent damage to the left main ostium, and the necessity of manipulation, which the operator may not be familiar with. Therefore, in our case we present a method, which involves the application of a regular Judkins Right 4 catheter for left main engagement. We propose that this method can be safely attempted prior to using telescoping techniques.

(C) 2017 The Society of Cardiovascular Academy. Production and hosting by Elsevier B.V. All rights reserved. This is an open access article under the CC BY-NC-ND license (http://creativecommons.org/licenses/by-nc-nd/4.0/).
\end{abstract}

\section{Introduction}

Although preshaped workhorse catheters have been successfully used over the years to perform coronary angiography, in some situations, catheters of different sizes and shapes may be necessary to engage the coronary ostia. The choice of catheters used is based on the specific anatomy of the aortic root and location of the coronary ostia to ensure a safe procedure and avoid complications. Enlargement of the ascending aorta is a situation in which even the largest catheter possible might fail to reach the left main coronary artery. Therefore, difficulty with access to the left main coronary artery continues to be a problem even today.

\section{Case}

We present the case of a 60 -year-old man who was referred for coronary angiography for the evaluation of stable angina. After achieving right femoral access using a 6-Fr sheath, we could not engage the left main (LM) using a 6-Fr Judkins Left 4 (JL) diagnostic catheter, which fell short of the left sinus of valsalva. An aortagram revealed a giant aortic aneurysm measuring $8 \mathrm{~cm}$ in diameter with heavy calcification and moderate aortic regurgitation, findings that had not previously been reported by the referring physician (Fig. 1A). Because the JL 4 catheter failed to the reach the left sinus of valsalva, we re-tried catheterization

\footnotetext{
* Corresponding author at: Sişli Hamidiye Etfal Education and Research Hospital, Department of Cardiology, Sisli, 34377 Istanbul, Turkey.

E-mail address: Serhat.Sigirci@sislietfal.gov.tr (S. Sığırcı).

Peer review under responsibility of The Society of Cardiovascular Academy.
}

using JL 5-6, Amplatz Left 3, and Extra-backup 4.5 catheters (Medtronic, MN) respectively; however, all these fell short of the LM ostium (Fig. 1B). Since the manufacturing companies did not produce bigger sizes and owing to the horizontal displacement of the enlarged ascending aorta, we decided to try 6-Fr Judkins Right (JR) catheter which had better support from the outer curvature of the aorta and engaged the left main ostium without much effort (Fig. 1C-D). The rest of the procedure including the right coronary artery injections was completed uneventfully.

\section{Discussion}

In patients presenting with severe aortic enlargement, it may be difficult to advance catheters into the LM ostium. JL catheter which has preshaped three curves is basically designed to engage the left main without much manipulation. However in aortic enlargement, these three curves make the catheter bend onto itself and lead to free floating in the ascending aorta. Therefore in severe cases, it is almost impossible to reach the left sinus of valsalva. JR with its two shallow curves does not bend too much and may allow for further manipulation. Previous case reports described use of the mother-in-child method in which a catheter of a smaller diameter was telescoped through one with a larger diameter. ${ }^{1,2}$ However, this technique is associated with a few drawbacks: (i) Friction caused by this method can impede the advancement of the inner catheter. (ii) Because the space between the catheters is small, the likelihood of thrombus formation within the catheters is a concern. (iii) Approaching the LM in a co-axial fashion may not be possible, which further jeopardizes the procedure. ${ }^{3}$ Roth GA et al. attempted to overcome these drawbacks by applying the same method with the use of a rapid-exchange guideliner catheter, ${ }^{2}$ which eliminates 


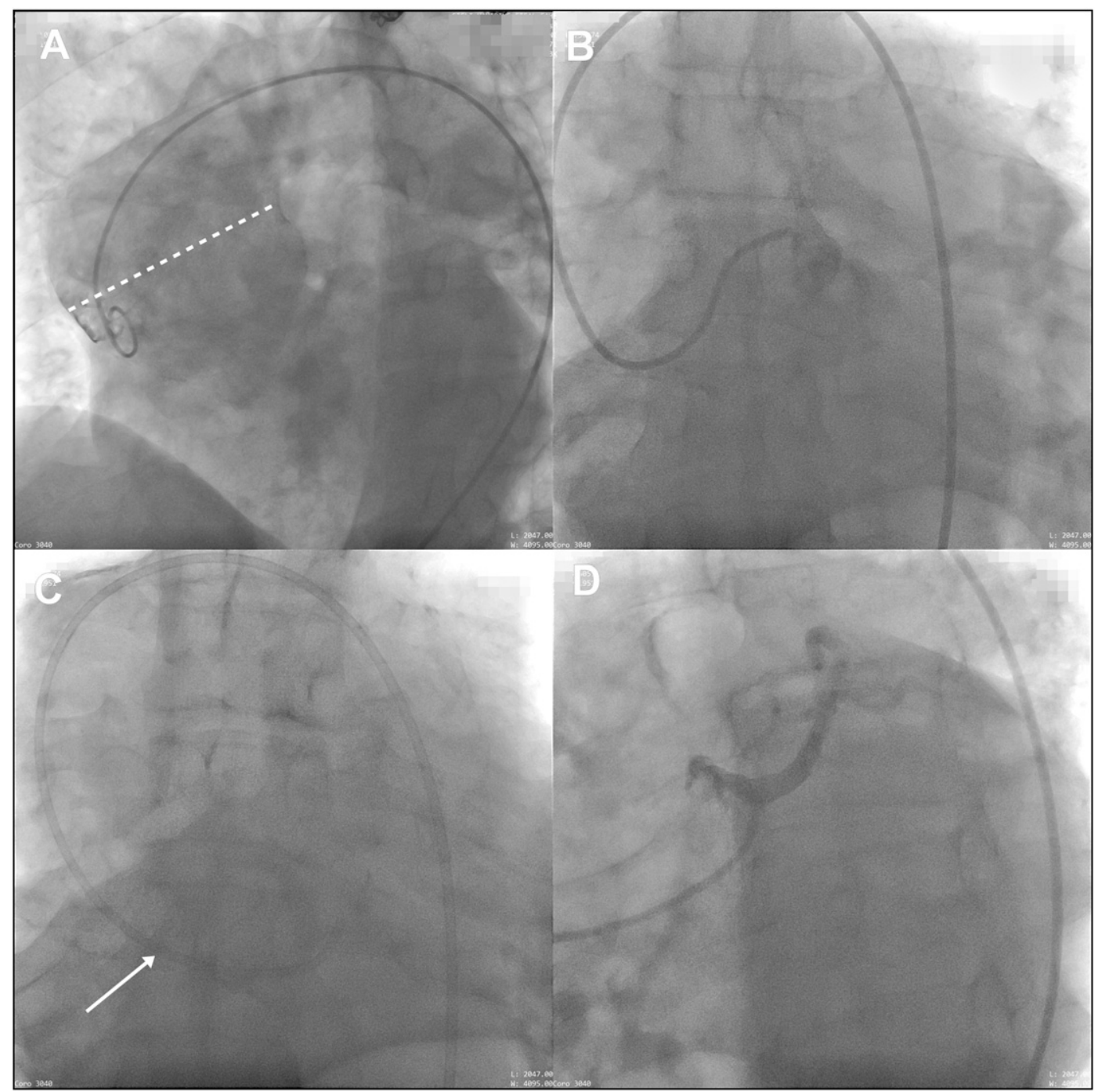

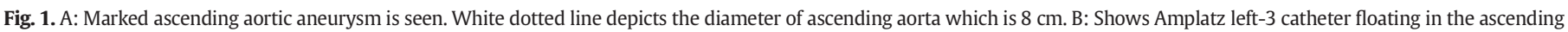
aorta. C: Judkins right catheter is seen in a horizontal position. White arrow points to the horizontal part. D: Left main coronary artery engaged by the Judkins right catheter.

some of the concerns related to use of the conventional mother-in-child technique. However, the soft tip of this monorail catheter is primarily designed for intracoronary delivery, and therefore it may not be possible to direct this catheter into the LM ostium through a catheter that is hanging freely in the ascending aorta. Furthermore, these manipulations require skill and experience and are associated with an increased risk of complications if performed by relatively new and inexperienced operators. We think that it is prudent to try JR- 4 catheter prior to attempting telescoping techniques. This catheter may successfully reach the left sinus of valsalva in an elongated and horizontally displaced aorta and with its short tip may co-align with the outer curvature of the aortic wall and once it is within the vicinity of the LM, it can be further manipulated. Therefore, in patients presenting with a giant aortic aneurysm that precludes the use of left catheters, a JR- 4 catheter may offer a practical solution.

\section{Acknowledgements}

None.

\section{Conflict of interest}

None.

\section{References}

1. Monopoli DE, Politi L, Sangiorgi GM, Modena MG. Modified mother-child technique for selective cannulation of complex take-off left coronary artery. J Cardiovasc Med (Hagerstown) 2010;11:514-516.

2. Anantharaman R, Obaid D, Chase A. Telescoping catheter technique for enlarged aortas. Catheter CardiovascInterv 2009;74:1126-1128.

3. Seth A, Kumar V. The art and science of coronary angiography ...... still exists! Catheter Cardiovascinterv 2012:80:1221-1222. 